\section{A tradição do trabalbo: a experiência dos metalúrgicos do Rio de Janeiro}

José Ricardo RAMALHO e Marco Aurélio SANTANA (orgs.). Trabalho e tradição sindical no Rio de Janeiro: a trajetória dos metalúrgicos. Rio de Janeiro, DP\&A /Faperj, 2001. 317 páginas.

\section{Iram Jácome Rodrigues}

O cenário é o Rio de Janeiro do século XX. O enredo é o mundo do trabalho. O olhar está voltado para os metalúrgicos da antiga capital federal, mas no horizonte, o que se nos apresenta é a experiência multifacetada das classes trabalhadoras no Brasil.

O livro organizado por José Ricardo Ramalho e Marco Aurélio Santana, intitulado Trabalbo e tradição sindical no Rio de Janeiro: a trajetória dos metalúrgicos, realiza um amplo estudo sobre um setor das classes trabalhadoras que possui reconhecida experiência de luta e que, por todo o século passado, em maior ou menor grau, esteve presente nos principais momentos da história política e social do país.

O estudo é composto de oito capítulos. Seus autores percorrem um amplo itinerário de questões, tais como: as vicissitudes da construção de uma identidade como classe trabalhadora; o tema do corporativismo estatal; a relação entre o "velho" e o "novo" sindicalismo, entre os velhos e novos militantes; a questão da organização por local de trabalho; as dificuldades da ação sindical em tempos de reestruturação produtiva; os conflitos no interior do sindicato e no âmbito da categoria; o papel desempenhado pela memória no processo de formação dos trabalhadores; a questão da gestão do trabalho; a compreensão da instituição sindical como espaço de cidadania; enfim, o papel desempenhado pelos metalúrgicos do Rio de Janeiro em sua atuação sindical e o desdobramento de sua ação na arena social e política do país.

Assim, a reflexão sobre as práticas desse agrupamento de trabalhadores no Rio de Janeiro e seu organismo de representação ajuda a iluminar muitas das questões relacionadas à ação sindical e ao futuro do trabalho no Brasil.

Antonio Candido, em seu clássico Os parceiros do Rio Bonito, observa:

"[...] não hesitei pois em situar o grupo estudado tanto na perspectiva histórica, quanto no complexo de problemas que hoje caracterizam a vida rural brasileira.

Como o leitor verá, quando falo nos membros do grupo que estudei, estou, a cada momento, pensando no caipira, em geral; e, reciprocamente, quando procuro compor esta abstração metodologicamente útil, a experiência real que a comprova é, sobretudo, a do grupo que estudei (Candido, 1964, p. 6, grifo no original).

Parafraseando Antonio Candido, poderíamos dizer que Trabalho e tradição sindical no Rio de Janeiro, ao fazer um estudo, sob múltiplos aspectos, do cotidiano operário e sua relação com a ação sindical em uma dada categoria estaria refletindo também sobre os trabalhadores em geral e, à medida que discorre sobre as classes trabalhadoras, o que daria realidade à sua experiência seria, principalmente, os operários metalúrgicos do Rio de Janeiro.

O trabalho está dividido em duas partes. $\mathrm{Na}$ primeira, sob o título de "Trabalhadores, fábricas e sindicatos", são apresentados os seguintes capítulos: "Tradição sindical e as mudanças econômicas dos anos 90: o caso dos metalúrgicos do Rio de Janeiro", de José Ricardo Ramalho e Marco Aurélio Santana, que à luz das mudanças recentes na organização do trabalho e da produção, do impacto dessas transformações na ação sindical e utilizando entrevistas com dirigentes sindicais do passado e do presente tendo como pano de fundo a história sindical dos trabalhadores metalúrgicos do Rio de Janeiro no século XX, faz uma reflexão sobre os dilemas vividos pelos trabalhadores metalúrgicos nos dias atuais. Em que medida a reestruturação produtiva está eliminando postos de trabalho? Como a ação sindical deste setor trabalhista está lidando com esta questão? De um lado, uma concepção que apostaria na abertura para a sociedade, ou seja, "para fora" e, de outro, uma visão que procura, diante das dificuldades, firmar uma relação mais 
estreita com a categoria metalúrgica, vale dizer, "para dentro". Os autores, no entanto, mostram que estas tentativas não têm conseguido dar respostas satisfatórias para a ação sindical e, certamente, ante a experiência "político-organizativa da categoria, a alternativa possível seria a articulação entre o 'dentro' e o 'fora' do universo sindical, combinando a luta pela melhoria das condições de vida e trabalho com os debates mais gerais sobre os destinos da sociedade brasileira" (p. 43).

O capítulo seguinte, "A construção da 'família siderúrgica': gestão paternalista e empresa estatal", de Regina Lúcia Morel, discorre sobre a formação dos trabalhadores metalúrgicos da Companhia Siderúrgica Nacional em Volta Redonda e analisa as estratégias empresariais para a criação da chamada "família metalúrgica". Citando o primeiro presidente da CSN, General Edmundo Macedo Soares para quem o problema brasileiro era "o povo sem formação construir no país os instrumentos de grandeza com que sonhavam as elites que tinham passado pelas escolas superiores", a autora procura refletir sobre as ambigüidades entre a gestão paternalista estatal e as demandas trabalhistas - ainda que incipientes - nos primeiros anos da Companhia Siderúrgica Nacional para demonstrar que a gestão paternalista não teria sido interiorizada "passivamente por todos os segmentos da empresa [...] ao discurso de que a CSN oferecia o que nenhuma empresa concedia aos seus empregados; foram-se, aos poucos, colocando mobilizações que reivindicavam o direito à participação e às condições de acesso à cidadania ainda que "regulada'" (pp.74-75).

O texto de Elina Pessanha, "Metalúrgicos, sempre operários navais", trata da tradição de organização desse setor que remonta ao século XIX. Tendo presente essa trajetória, a autora vai fixar em alguns momentos político-organizativos dessa categoria seu desenvolvimento e os principais problemas enfrentados pelos operários navais nos dias de hoje, diante do processo de crise dos estaleiros a partir dos anos de 1980 e que se acentua nos anos de 1990. Essa crise é uma decorrência da abertura comercial, da privatização e do processo de reestruturação que levaram a um forte declínio os números de trabalhadores neste se- tor - de repente, estes operários se viram como se fossem deserdados das fábricas, ou, como observa Elina Pessanha, como os "sem-fábricas". Em 1979, eram cerca de 40 mil operários; em 1997, existiam tão-somente "2.641 trabalhadores em empregos diretos” (pp. 97-98). A autora chama a atenção para o fato de que esses trabalhadores foram importantes para a criação de uma "cultura de direitos" no Brasil e, hoje, no entanto, estão à deriva, o que ilustra "perspectivas que se fecham ou se abrem - para a classe trabalhadora. Diante das mudanças na composição da classe operária em face das adaptações produtivas e da precarização e também, no limite, da sua quase total desarticulação, tendo como pano de fundo a retração econômica e a desregulamentação das relações de trabalho, parece tornar imprescindível definir, na prática, mecanismos de construção de novas identidades de classe e formas também inovadoras de atuação sindical" (p. 102).

O capítulo 4 traz um texto de José Ricardo Ramalho, "Metalúrgicos do Rio de Janeiro e a repressão política do pós-1964". A partir dos dados constantes nos Inquéritos Policiais Militares (IPMs) durante o período da ditadura militar em nosso país, que tratavam da repressão policial-militar aos sindicalistas metalúrgicos e de entrevistas com operários que viveram essa experiência, o autor procura refletir sobre os acontecimentos daquele período, contrapondo as interpretações desses anos de chumbo. Sobre essa época, relembra um dos entrevistados:

Depois de 1964 eu passei aqueles anos todos amargurado, sem ajuda de ninguém. Comi o pão que o diabo amassou. Fui até certo ponto humilhado por alguns companheiros e também ninguém me ajudou nesse período. Essa é a verdade. Até 1979. A ajuda que eu tive foi de um padre, que não me conhecia antes. Quando me conheceu eu estava trabalhando escondido (L.U.) (p. 126).

O autor mostra que as delações, muitas vezes, expressavam lutas políticas anteriores, entre as várias facções em disputa no sindicato, particularmente, o ódio de setores da Igreja no pré-1964 aos comunistas que tiveram, naquele período, uma influência muito grande entre os metalúrgi- 
cos e o conjunto dos trabalhadores do Rio de Janeiro e também do Brasil. Enfim, como analisa José Ricardo Ramalho, "no caso dos metalúrgicos do Rio de Janeiro, o estudo da repressão a seus militantes mostra a complexidade dos dados disponíveis e possibilita um exercício de investigação histórico-sociológica que se compromete com a elucidação de silêncios e o reconhecimento de conflito e competição entre versões diferentes da história" (p.129).

A segunda parte do livro, "Sindicato dos Metalúrgicos - diversas fases de uma trajetória", faz um apanhado histórico da ação sindical e também da instituição sindical dos metalúrgicos do Rio de Janeiro do início do século XX até quase o seu final. Esta parte se inicia com o texto de Eduardo Stoltz, "Sindicato dos metalúrgicos e a construção da identidade coletiva do grupo operário (19171945)". Nele o autor mostra a trajetória das lutas dos trabalhadores pari passu com a construção/organização do sindicato dos metalúrgicos nos seus variados momentos. A partir de jornais da época, é mostrada a movimentação operária, retratadas as condições de trabalho desse contingente operário e as tentativas de organização da classe trabalhadora.

Entre fins de 1902 e início de 1903, o jornal Gazeta Operária estampava em suas colunas várias denúncias sobre as péssimas condições de trabatho nas oficinas de fundição. Em fevereiro de 1903, o mesmo jornal anunciava a convocatória de uma assembléia para constituir a Associação de Fundidores, cujos estatutos provisórios foram então apresentados. Essa entidade, aparentemente, não conseguiu estabilizar-se (p. 135).

Notícias esparsas nos jornais operários, à época, assim como nos jornais da grande imprensa dão conta dessa movimentação trabalhista. As condições criadas pela crise vivida durante a Primeira Guerra Mundial e as lutas operárias daquele período foram fundamentais para que os trabalhadores metalúrgicos conseguissem organizar seu sindicato em 1917, conhecido inicialmente como União Geral dos Operários Metalúrgicos. Assim, neste capítulo, o autor refaz a história do sindicato dos metalúrgicos de 1917 a 1945, procurando ressaltar os principais momentos da ação sindical desses trabalhadores naquele período, relacionando-o com a construção da identidade coletiva desse agrupamento de trabalhadores.

O texto de Marco Aurélio Santana, "Trabalhadores e militância sindical", chama a atenção para a difícil relação entre partido/sindicato/classe no âmbito da ação sindical dos metalúrgicos do Rio de Janeiro de 1945 a 1964. Ressalta o papel desempenhado pelo Partido Comunista Brasileiro, suas relações com o trabalhismo, as lutas mais significativas que foram levadas adiantes pelos trabalhadores naquele momento e as várias formas de inserção do PCB no período em questão: a luta pelo retorno ao espaço sindical (1947-1950); a tentativa da ocupação do espaço sindical (1950-1954); o período que se seguiu ao suicídio de Vargas e a mudança na ação dos comunistas (1954-1955); a política de unidade (1955-1964); e, finalmente, a atuação dos comunistas à frente do sindicato (1963-1964). Além disso, Marco Aurélio Santana mostra, de forma destacada, o trabalho levado adiante pelos comunistas no interior da categoria metalúrgica com o objetivo de organizar os trabalhadores em seus locais de trabalho e nos conselhos sindicais de empresa.

A análise da atuação da militância comunista no seio da categoria metalúrgica indica que, desde o fim da intervenção governamental e seu retorno ao espaço sindical (1950) até a formalização de sua entrada na direção da entidade, a partir da conformação da aliança competitiva (1955), que seguirá à frente do sindicato no período 1955 1964, os comunistas tinham como centro de sua política a constituição, propagação e ocupação dos conselhos sindicais de empresa (p. 196).

Essas formas organizativas no interior das empresas estiveram na raiz das greves de 1955 , 1957, e da campanha salarial de 1962, como observa Santana (p. 199).Em síntese, para o autor, a atuação dos comunistas no interior do sindicato dos metalúrgicos foi crucial para o crescimento da organização pela base dessa categoria. Esse processo não foi linear. No interior do PCB ocorreram muitos conflitos entre a direção e a militância comunista que atuava junto aos metalúrgicos; outro fato relevante, para o entendimento desse perío- 
do, é aliança entre PCB e PTB na ação sindical; finalmente, o papel desempenhado pelos conselhos sindicais de empresa: ao mesmo tempo em que eram importantes para a ação sindical, na relação entre patrões e empregados, funcionava, por vezes, como instrumento de pressão e/ou controle da direção sindical.

O texto de Francisco Carlos Palomanes Martinho, "O estatismo sindical e a transição democrática", faz um estudo sobre o sindicato dos metalúrgicos no período de 1974 a 1985. O autor procura refletir sobre a contradição entre o "discurso" e a "prática" dos grupos de oposição que faziam uma crítica mais contundente à política da diretoria do sindicato neste período e que, em larga medida, engrossaram as fileiras do "novo sindicalismo". Esses setores oposicionistas que "criticam o "eleitoralismo' e as mobilizações exclusivamente 'econômicas' acabam por se submeter à lógica de uma dinâmica menos 'politizada' e mais 'sindicalista'. O autor discute os principais acontecimentos da ação sindical no período à luz do cotidiano do sindicato dos metalúrgicos do Rio de Janeiro e mostra as dificuldades que, até aquele momento, vivia o padrão de ação sindical que estava mais próximo do que se convencionou chamar de novo sindicalismo. A questão presente aqui estaria relacionada com a estrutura sindical corporativa. Na experiência dos metalúrgicos, entre 1974 e 1985, Martinho observa que "o controle exercido pelo Estado e por suas diversas instâncias não conseguiu ser eficientemente questionado. As chamadas "bases" poucas vezes se mobilizaram. Mas, quando o fizeram, a referência procurada era no sindicato oficial. Para as lideranças, mesmo aquelas que questionavam o modelo, restava apenas lutar "por dentro da trincheira adversária' para, se pudesse, transformá-la. Mais do que isso, entretanto, acabaram por ela transformados" (p. 246).

O último capítulo da coletânea é escrito por Regina Helena Malta Nascimento e se chama "O sindicato dos metalúrgicos do Rio de Janeiro nos anos 1980". A autora observa que

Em meados dos anos de 1970 começaria a se organizar mais uma vez, e novamente a partir da movimentação no interior das fábricas, uma articulação de base, independente da direção do sin- dicato, que mais tarde iria se constituir em movimentos de oposição. Esse processo de luta pela retomada do sindicato para sua "tradição de luta", e também obviamente pela reconquista das liberdades democráticas e de organização, que se inicia na resistência no interior das fábricas, se desdobra na greve de 1979 e nos movimentos de oposição sindical, [leva à formação de] uma nova geração de militantes, que atua durante toda a década de 1980 e chega à direção do sindicato em 1988, propugnando um "novo sindicalismo" (pp. 252-253).

O texto trata, especificamente, da passagem de um sindicalismo de colaboração, expressão do sindicalismo do pós-1964, para o surgimento do chamado novo sindicalismo no interior das fábricas metalúrgicas do Rio de Janeiro, e do papel desempenhado por esse padrão de ação sindical à frente do sindicato dos metalúrgicos no período de 1987 a 1992. Regina Nascimento faz uma interessante distinção entre novos e velhos sindicalistas. Poderíamos dizer, entre o velho sindicalismo (pré-1964) e o novo sindicalismo (pós-1978), procurando entender os pontos de rupturas e/ou de continuidades entre estas duas práticas sindicais, ao mesmo tempo em que abre pistas para o entendimento de estratégias de construção de identidades de grupos de trabalhadores em momentos históricos distintos.

Alguns temas perpassam, direta ou indiretamente, as preocupações dos autores. O primeiro diz respeito à questão da estrutura sindical corporativa; o segundo está relacionado ao tema da representação dos trabalhadores em seus locais de trabalho; o terceiro - um dos principais diálogos deste estudo - discute a relação entre o sindicalismo do período anterior a 1964 e o padrão de ação sindical que começa a se instaurar no país após as greves de 1978, o chamado novo sindicalismo e, por fim, um aspecto que está presente em vários capítulos, a relação entre sindicalismo e as conseqüências do processo de reestruturação produtiva - e que significa, em larga medida, o aumento da precarização das condições de trabalho para amplas parcelas da população assalariada, baixos salários e um aumento continuado do desemprego, condenando significativos setores das classes trabalhadoras a uma vida de desesperança. 
Trabalho e tradição sindical no Rio de Janeiro, ao mesmo tempo em que traça um painel das principais lutas do sindicalismo metalúrgico fluminense, explicita muitos dos aspectos cotidianos da vida operária no século XX. O que emerge não são apenas os momentos "gloriosos" desses trabalhadores, suas vitórias e conquistas, mas também, suas derrotas, dificuldades e dilemas. São indivíduos de carne e osso que se emocionam, se confrontam e negociam com os empregadores em momentos de greve; enfrentam, por vezes, o aparelho repressivo do Estado e também apóiam Getulio e o PTB.

A trajetória das classes trabalhadoras não é algo retilíneo, expressão dos grandes feitos, mas, em alguma medida, a difícil resultante da construção de uma vontade coletiva eivada de contradições, fragmentações e rupturas, onde a experiência das pequenas lutas, da sociabilidade no local de trabalho, na família, no bairro e no sindicato também conta muito. Vale dizer, a identidade é plural e não singular.

Enfim, a partir do estudo da experiência dos metalúrgicos do Rio de Janeiro a pergunta que nos fazemos é se é possível - nos dias de hoje forjar uma clara identidade coletiva como, em certo sentido foi possível no passado, diante de um quadro que, em muitos aspectos, é extremamente desfavorável ao mundo do trabalho: a diminuição sem precedentes do número de trabalhadores industriais, uma organização incipiente no interior das empresas, um modelo de relação capital/trabalho que, entre outros aspectos, não permite a liberdade sindical e o desemprego funcionando como um inibidor da ação dos trabalhadores no âmbito sindical. Estes são, sem dúvida, alguns dos desafios para o sindicalismo nestes tempos difíceis de transformações da organização do trabalho, da produção e da estrutura ocupacional tangidos pelas ondas da desregulamentação das relações de trabalho.

\section{IRAM JÁCOME RODRIGUES é professor do Departamento de Economia da Universidade São Paulo.}

\section{Mulberes, diferenças e desigualdades}

Suely KOFES. Mulher, mulheres: identidade, diferença e desigualdade na relação entre patroas e empregadas. Campinas, Editora da Unicamp, 2001. 470 páginas.

Suely KOFES. Uma trajetória, em narrativas. Campinas, Mercado de Letras, 2001. 192 páginas.

Júlio Assis Simões

Estes dois trabalhos - produzidos em momentos distintos da carreira da antropóloga, professora e pesquisadora da Unicamp, e circunstancialmente publicados quase ao mesmo tempo - dão-nos a oportunidade de acompanhar o desdobramento de uma contribuição de considerável relevância em relação ao panorama atual dos estudos de gênero, permitindo situar as singulares conexões destes com a antropologia. Ambos dão testemunho do papel privilegiado da antropologia, tanto em incitar como questionar os pressupostos dos estudos de gênero, mesmo antes que esse rótulo se popularizasse em nossa produção acadêmica. Como Suely Kofes assinala, no prefácio a Mulher, mulheres, reportando-se ao tempo em que preparava o trabalho de doutorado que originou o livro: "Quando escrevi a tese, eu nada conhecia sobre as chamadas 'teorias contemporâneas de gênero'. Meus argumentos sustentaram-se nas contribuições da antropologia sobre as distintas conceituações da diferença sexual inscritas em mitos, nos sistemas e práticas de parentesco, nos rituais, em sistemas classificatórios, na organização da produção, nas concepções de pessoas, nas relações e interações sociais etc." (p. 21) Apesar disso - ou, talvez, também por causa disso - é patente o empenho da autora em desenvolver interpretações desafiadoras que convergem com o que há de mais interessante nas reflexões atuais sobre gênero, no que se refere ao esforço de desconstruir categorias e relações supostamente fixas e naturalizadas pela diferença sexual, e recontextualizá-las em termos históricos e culturais. 